ECLETICA A

www.scielo.br/eq

www.ecletica.iq.unesp.br

Volume 33, número 3, 2008

\title{
Polarographic study and electrode kinetics of [Zn(II) - antibiotics - cephaloglycin] system vis a vis kinetics of electrode reactions
}

\author{
F. Khan* \\ Electrochemical Laboratory, Department of Chemistry, Dr. H. S. Gour University, Sagar 470 003, M. P. India \\ *faridkhan58@yahoo.com
}

\begin{abstract}
Electrode kinetics and complex formation of $\mathrm{Zn}(\mathrm{II})$ using doxycycline, chlortetracycline, oxytetracycline, tetracycline, minocycline, amoxicillin, chloramphenicol and cephaloglycin were reported at $\mathrm{pH}=7.30 \pm 0.01 \mathrm{in}=1.0 \mathrm{molL}^{-1} \mathrm{NaClO}_{4}$ used as supporting electrolyte at $25.0^{\circ} \mathrm{C}$. Kinetic parameters viz. transfer coefficient $(\alpha)$, degree of irreversibility $(\lambda)$ and rate constant $(\mathrm{k})$ were determined. The study showed that 'Transition state' behaves between reactant $(\mathrm{O})$ and product $(\mathrm{R})$ response to applied potential. The stability constants varied from 2.14 to 10.31 showing that these drugs or their complexes could be used against $\mathrm{Zn}$ toxicity.
\end{abstract}

Keywords: Electrode kinetics; zinc-antibiotics-cephaloglycin system; binary and ternary complexes.

\section{Introduction}

In voltammetry, both mass transfer and charge transfer reactions are important [1-2]. In normal chemical reactions, the free energy brings the reactants from their initial position to the transition state. In electrochemical reactions (oxidants and reductants), the potential difference applied, affects the electrokinetic reactions and hence, the summit of the energy barrier (transition state) is affected but the energy barrier adjusts itself in such a way that it always lies in the mid way between oxidants and reductants between dropping mercury electrode and solution interface [3-4]. A small variation in potential not only affects the rate of the reaction but also rate constant greatly. The electrical double layer formed in the vicinity of d.m.e. is an interesting topic of discussion [5-6]. On the other hand, antibiotics like doxycycline, chlortetracycline, oxytetracycline, tetracycline, minocycline, chloramphenicol and cephaloglycin are important drugs used against serious diseases [7-8] ; therefore, the author has studied the ternary complex system [ $\mathrm{Zn}$ - antibiotics - cephaloglycin] and its kinetics on the basis of stability constants and kinetic parameters for which no reference is traced out so far in the literature.

\section{Experimental details}

Apparatus and reagents

All the chemicals used were of A. R. grade and their solutions were prepared in doubly distilled water. Antibiotics were purchased from Fluka, Aldrich and Sigma and used as such without further purification. The concentrations of $\mathrm{Zn}$ (II) $\left\{\mathrm{ZnCl}_{2}\right.$, Fluka $\}, \mathrm{NaClO}_{4} \cdot \mathrm{H}_{2} \mathrm{O}$ (Fluka) and Triton $\mathrm{X}-100$ (Loba Chemie) in the analyte were 0.5 mmol L-1, $1.0 \mathrm{~mol} \mathrm{~L}^{-1}$ and $0.001 \%$ respectively. 
Pure hydrogen gas was passed through the analyte for deaeration before recording the current - voltage data. $\mathrm{Zn}$ (II) and ligands were taken in the ratio of 1: 40 in case of binary complexes and 1:40:40 in case of ternary complexes and current - voltage curves were drawn at $\mathrm{pH} 7.10-8.80$; it has been observed that the maximum shift of $E_{1 / 2}$ was observed at $\mathrm{pH} 7.20$ to 8.50 but $\mathrm{pH}=7.30 \pm 0.01$ was selected on account of studying the complexes in human blood $\mathrm{pH}$ [9]. $\mu \mathrm{pH}$ meter (Systronics Model - 361) was used to measure the $\mathrm{pH}$ of the analyte at $7.30 \pm 0.01$ adjusted with dilute solutions of $\mathrm{NaOH}$ or $\mathrm{HClO}_{4}$ (both B.D.H.) as required. Current - voltage curves were obtained on a Polarographic analyzer (Elico CL - 362). The capillary was of $5.0 \mathrm{~cm}$ in length with diameter 0.06 $\mathrm{mm}$ with $\mathrm{m}^{2 / 3} \mathrm{t}^{1 / 6}=2.40 \mathrm{mg}^{2 / 3} \mathrm{~s}^{-1 / 2}$. Three electrodes system was used. Potassium dihydrogen phosphate - sodium hydroxide buffer was added in the analyte to stabilize the $\mathrm{pH}$ of the analyte at 7.30.

\section{Results and discussion}

$\mathrm{Zn}$ (II) and its complexes[10] gave well defined two electron quasireversible reduction wave in $1.0 \mathrm{~mol} \mathrm{~L}^{-1} \mathrm{NaClO}_{4}$ (S.E.) and $0.001 \%$
Triton $\mathrm{X}-100$ as suppressor at $\mathrm{pH}=7.30 \pm 0.01$ at $25.0^{\circ} \mathrm{C}$. Devaries and Kroon method [11] was used to determine the number of electrons involved in the reduction [ $\mathrm{Zn}$ - cephaloglycin] system.

The concentration of cephaloglycin in the analyte was varied from $5 \mathrm{mmol} \mathrm{L}^{-1}$ to $20 \mathrm{mmol}$ $\mathrm{L}^{-1}$. The $\mathrm{E}_{1 / 2}$ values increased with increase of concentration of cephaloglycin to $\mathrm{Zn}$, showed complex formation. Gellings method [12] was used to determine $\mathrm{E}_{1 / 2}$ reversible values from $\mathrm{E}_{1 / 2}$ quasireversible values. Lingane method [13] confirmed the formation of $1: 1$ and $1: 2$ complexes with stability constant $\log \beta_{01}=2.14$ and $\log \beta_{02}=3.22$ respectively [ $\mathrm{Zn}$-antibiotics - cephaloglycin].

In this system, the concentration of antibiotics varied from $0.5 \mathrm{mmol} \mathrm{L}^{-1}$ to $30.0 \mathrm{mmol} \mathrm{L}^{-1}$. The half wave potential values became more negative with the addition of $0.025 \mathrm{~mol} \mathrm{~L}^{-1}$ and $0.05 \mathrm{~mol}$ $\mathrm{L}^{-1}$ of [cephaloglycin] to [ $\mathrm{Zn}-$ antibiotics] system showed the formation of ternary complexes [ $\mathrm{Zn}-$ antibiotics - cephaloglycin]. Gellings method was used to determine the $E_{1 / 2}$ reversible values from $\mathrm{E}_{1 / 2}$ quasireversible values. The current - voltage curves (polarograms) of [Zn-doxycycline - cephaloglycin] system at [cephaloglycin] $=0.025 \mathrm{~mol} \mathrm{~L}^{-1}$ are given in Fig. 1. The plots between $\left[\mathrm{E}-\mathrm{RT} / \mathrm{nF} \log \left(\mathrm{i}_{\mathrm{d}}-\mathrm{i}\right) / \mathrm{i}\right]$ vs. $\mathrm{i}$ are given in Fig. 2. Schaap and McMaster

Table 1. Polarographic characteristics and $\mathrm{F}_{\mathrm{ij}}[\mathrm{X}, \mathrm{Y}]$ values for $[\mathrm{Zn}$ - doxycycline - cephaloglycin] system*, Supporting electrolyte $=1.0 \mathrm{~mol} \mathrm{~L}-1 \mathrm{NaClO}_{4}, \mathrm{pH}=7.30 \pm 0.01, \mathrm{~T}=25.0^{\circ} \mathrm{C}$. [cephaloglycin] $=$ $0.025 \mathrm{~mol} \mathrm{~L}^{-1}$; [cephaloglycin] $=0.05 \mathrm{~mol} \mathrm{~L}^{-1}$.

\begin{tabular}{|c|c|c|c|c|c|c|c|c|c|c|c|c|}
\hline [Doxycy.] & $\log \operatorname{Im} / \mathrm{Ic}$ & $\mathrm{E}_{1 / 2}{ }^{\mathrm{r}}$ & $\mathrm{F}_{00}[\mathrm{X}, \mathrm{Y}]$ & $\mathrm{F}_{10}[\mathrm{X}, \mathrm{Y}]$ & $\mathrm{F}_{20}[\mathrm{X}, \mathrm{Y}]$ & $\mathrm{F}_{30}[\mathrm{X}, \mathrm{Y}]$ & $\log \operatorname{Im} / \mathrm{Ic}$ & $\mathrm{E}_{1 / 2}{ }^{\mathrm{r}}$ & $\mathrm{F}_{00}[\mathrm{X}, \mathrm{Y}]$ & $\mathrm{F}_{10}[\mathrm{X}, \mathrm{Y}]$ & $\mathrm{F}_{20}[\mathrm{X}, \mathrm{Y}]$ & $\mathrm{F}_{30}[\mathrm{X}, \mathrm{Y}]$ \\
\hline $\mathrm{X} 10^{3} \mathrm{~mol} \quad \mathrm{~L}^{-1} * *$ & & -V vs SCE & & $\mathrm{X} 10^{3}$ & $\mathrm{X} 10^{5}$ & $X 10^{5}$ & & -V vs SCE & & $\mathrm{X} 10^{3}$ & $\mathrm{X} 10^{5}$ & $\mathrm{X} 10^{5}$ \\
\hline 0.00 & - & 0.9850 & - & - & - & - & - & 0.9850 & - & - & - & - \\
\hline 0.50 & 0.00706 & 1.0215 & 16.58 & 22.19 & 15.88 & 162.18 & 0.01424 & 1.0350 & 52.07 & 80.04 & 30.98 & 162.18 \\
\hline 1.00 & 0.00706 & 1.0275 & 28.48 & 22.99 & 15.96 & 162.18 & 0.02153 & 1.0425 & 93.65 & 81.60 & 31.06 & 162.18 \\
\hline 2.00 & 0.01424 & 1.0355 & 54.73 & 24.62 & 16.12 & 162.19 & 0.02896 & 1.0505 & 181.53 & 84.74 & 31.22 & 162.18 \\
\hline 3.00 & 0.01424 & 1.0415 & 84.34 & 26.28 & 16.28 & 162.17 & 0.03651 & 1.0560 & 275.79 & 87.91 & 31.38 & 162.17 \\
\hline 4.00 & 0.02153 & 1.0455 & 117.40 & 27.97 & 16.44 & 162.17 & 0.04420 & 1.0595 & 376.52 & 91.11 & 31.54 & 162.19 \\
\hline 5.00 & 0.02153 & 1.0490 & 154.01 & 29.70 & 16.61 & 162.20 & 0.04420 & 1.0630 & 483.82 & 94.35 & 31.71 & 162.16 \\
\hline 6.00 & 0.02896 & 1.0515 & 194.27 & 31.46 & 16.77 & 162.16 & 0.05202 & 1.0655 & 597.79 & 97.62 & 31.87 & 162.20 \\
\hline 8.00 & 0.02896 & 1.0565 & 286.11 & 35.07 & 17.09 & 162.18 & 0.05999 & 1.0695 & 846.11 & 104.25 & 32.19 & 162.18 \\
\hline 10.00 & 0.03651 & 1.0605 & 393.70 & 38.82 & 17.42 & 162.18 & 0.05999 & 1.0730 & 1122.26 & 111.02 & 32.52 & 162.18 \\
\hline 20.00 & 0.04420 & 1.0745 & 1195.23 & 59.48 & 19.04 & 162.18 & 0.05999 & 1.0855 & 2947.79 & 146.78 & 34.14 & 162.18 \\
\hline 30.00 & 0.05202 & 1.0835 & 2507.34 & 83.39 & 20.66 & 162.17 & 0.05999 & 1.0935 & 5585.93 & 185.79 & 35.76 & 162.18 \\
\hline
\end{tabular}

$\log \mathrm{A}=0.74, \log \mathrm{B}=4.33, \log \mathrm{C}=6.20, \log \mathrm{D}=7.21, \log \mathrm{A}=1.08, \log \mathrm{B}=4.89, \log \mathrm{C}=6.49, \log \mathrm{D}=7.21$

$* *\left\{\right.$ doxycy.] $=1.00 \times 10^{-3} \mathrm{~mol} \mathrm{~L}-1$, therefore; $1.00=$ [doxycy.] $\left.\times 10^{3}\right\}$

*(The data for other systems can be obtained on request.) 
method [14] confirmed the formation of 1:1:1, 1:2:1 and 1:1:2 complexes. The data and plots for $\mathrm{F}_{\mathrm{ij}}[\mathrm{X}, \mathrm{Y}]$ vs. $[\mathrm{X}]$ for $[\mathrm{Zn}$ - doxycycline - cephaloglycin] system \{where $\mathrm{X}$ and $\mathrm{Y}$ are doxycycline and cephaloglycin and $\mathrm{i}$ and $\mathrm{j}$ are their stoichiometric numbers respectively\} were given in Table 1 and Fig. 3 respectively. The values of stability constant of complexes are given in Table 2.

For comparison of the stability of binary and ternary complexes, the values of mixing constant $\log \mathrm{K}_{\mathrm{m}}$ were determined as follows

$\log \mathrm{K}_{\mathrm{m}}=\log \beta_{11}-1 / 2\left[\log \beta_{20}-\log \beta_{02}\right][14]$

for the reaction $2[\mathrm{Zn}$ (doxycy.) (cephalogly.)] $\Leftrightarrow$ $\left[\mathrm{Zn}(\text { doxycy. })_{2}\right]+\left[\mathrm{Zn}(\text { cephalogly. })_{2}\right]$.

The values of $\log \mathrm{K}_{\mathrm{m}}$ were 0.25 , - 0.79 , 0.51 and -0.43 for [ $\mathrm{Zn}-$ doxycycline - cephaloglycin], [Zn - oxytetracycline - cephaloglycin], [Zn - tetracycline - cephaloglycin] and [Zn minocycline - cephaloglycin] respectively. The positive values of $\log \mathrm{K}_{\mathrm{m}}$ showed that ternary complexes are more stable than their binary complexes while negative values showed that binary complexes are more stable than their ternary complexes. The complexes 1:1:1 in case of [ $\mathrm{Zn}$ - chlortetracycline - cephaloglycin], 1:2 in case of [ $\mathrm{Zn}-$ amoxicillin - cephaloglycin] and 1:1:1 in [Zn chloramphenicol - cephaloglycin] system was not formed therefore; the values of $\log \mathrm{K}_{\mathrm{m}}$ were not calculated for these systems.

The trend of stability constant of complexes was doxycycline < chlortetracycline < oxytetracycline $<$ tetracycline $<$ minocycline $<$ amoxicillin $<$ chloramphenicol. The structures of doxycycline, chlortetracycline, oxytetracycline, tetracycline and minocycline are same except in the difference in $\mathrm{R}_{1}, \mathrm{R}_{2}$ and $\mathrm{R}_{3}$ positions [15]. They all coordinate to the $\mathrm{Zn}$ ion through two oxygen atom, one of them the oxygen atom double-bonded to the carbon ring, and the other the oxygen atom belonging to the neighbor amide group. The stability constant of [Zn-doxycycline - cephaloglycin] system has the lowest values amongst all other complexes because this system has the lowest values of $E_{1 / 2}$ shift. The fact that the stability constants of chlortetracycline complexes are lower than those of oxytetracycline complexes is attributed to the presence of elec- tronegative $\mathrm{Cl}$ at $\mathrm{R}_{1}$ in former complex, whereas in the latter one the $R_{1}$ position is occupied by the electropositive hydrogen in place of $\mathrm{Cl}[16]$. The stability constants of [Zn-oxytetracycline-cephaloglycin] complexes are lower than those of [Zntetracycline-cephaloglycin]; fact that is attributed to the presence of $\mathrm{OH}$ - group in oxytetracycline at $R_{3}$ position. In case of tetracycline, $H$ is present both at $R_{1}$ and $R_{3}$ therefore; there is less electronic disturbance in tetracycline complex when compared to the complexes formed by substituted tetracyclines. This order of stability constants of tetracyclines is also supported the order of their $\mathrm{pK}$ values [17].The fact that the stability constant values of minocycline complexes are lower than those of amoxicillin complexes is attributed to the presence of thiazoline ring and Beta-lactum ring in amoxicillin. An increase in the number of rings within a chelate results in greater stability of chelate[18]. In case of amoxicillin, the $\mathrm{N}$ and oxygen of $-\mathrm{COOH}$ of thiazolidine ring may take part in coordination with $\mathrm{Zn}$ while the bonding in minocycline complexes is the same as tetracycline complexes making six membered ring with two double bonds. As the number of rings increases, the stability constant of complex increases [18]. The chloramphenicol made complexes of the maximum stability is due to the fact that this complex system has maximum shift of $\mathrm{E}_{1 / 2}$ that might be the result of the formation of one 4 and one 5 membered ring with $\mathrm{Zn}[18]$. In case of cephaloglycin, $\mathrm{O}$ of the $\mathrm{COOH}$ and $\mathrm{N}$ of the $\beta$-lactam ring may take part in bond formation with $\mathrm{Zn}$ making 5 membered ring. The structure of $[\mathrm{Zn}-$ doxycycline - cephaloglycin] system is given in Figure 4.

The values of Schaap and Mc Master functions can be determined as follows:

For ternary system

$\mathrm{M}+\mathrm{i} \mathrm{X}+\mathrm{j} \mathrm{Y}=\mathrm{M} \mathrm{Xi} \mathrm{Yj}$.

The values of function

$\mathrm{F}_{00}[\mathrm{X}, \mathrm{Y}]$ can be calculated by the following equation :

$\mathrm{F}_{00}[\mathrm{X}, \mathrm{Y}]=\left[0.435 \mathrm{nF} / \mathrm{RT}\left\{\left(\mathrm{E}_{1 / 2}\right)_{\mathrm{S}}-\left(\mathrm{E}_{1 / 2}\right)_{\mathrm{C}}\right\}\right]+$ $\log \mathrm{I}_{\mathrm{m}} / \mathrm{Ic}$ and

$\mathrm{F}_{10}[\mathrm{X}, \mathrm{Y}]=\mathrm{F}_{00}[\mathrm{X}, \mathrm{Y}]-\mathrm{A} /[\mathrm{X}]$

$\mathrm{F}_{20}[\mathrm{X}, \mathrm{Y}]=\mathrm{F}_{10}[\mathrm{X}, \mathrm{Y}]-\mathrm{B} /[\mathrm{X}]$

$-$

$-$

$\mathrm{F}_{\mathrm{N}, 0}[\mathrm{X}, \mathrm{Y}]=\mathrm{F}_{\mathrm{N}-1}[\mathrm{X}, \mathrm{Y}]-$ const./[X]. 
The function $\mathrm{F}_{00}[\mathrm{X}, \mathrm{Y}]$ can be expressed as:

$\mathrm{F}_{00}[\mathrm{X}, \mathrm{Y}]=\left\{\beta_{00}+\beta_{01}[\mathrm{Y}]+\beta_{02}[\mathrm{Y}]^{2}+\beta_{03}[\mathrm{Y}]^{3}\right\}[\mathrm{X}]^{0}$

$+\left\{\beta_{10}+\beta_{11}[\mathrm{Y}]+\beta_{12}[\mathrm{Y}]^{2}\right\}[\mathrm{X}]$

$+\left\{\beta_{20}+\beta_{21}[\mathrm{Y}]\right\}[\mathrm{X}]^{2}$

$+\left\{\beta_{30}\right\}[\mathrm{X}]^{3}$

The function $\mathrm{F}_{00}[\mathrm{X}, \mathrm{Y}]$ can be factorized
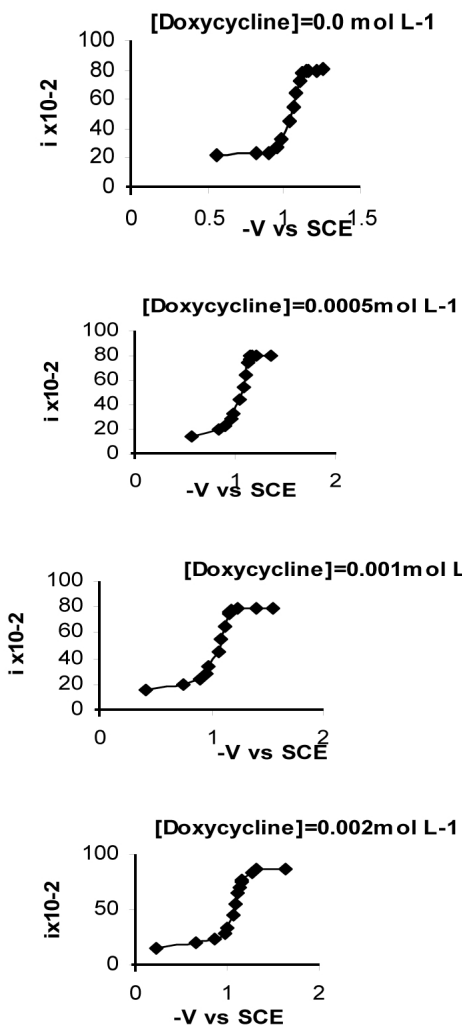

[Doxycycline $]=0.003 \mathrm{~mol} \mathrm{L-1}$
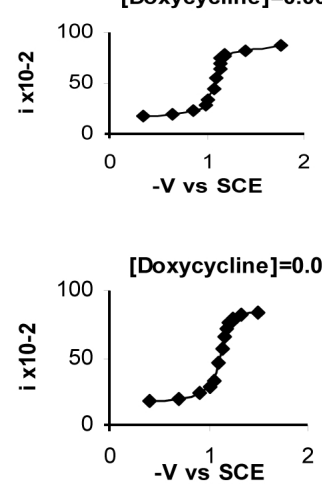

and written as $\mathrm{F}_{00}[\mathrm{X}, \mathrm{Y}]=\mathrm{A}+\mathrm{B}[\mathrm{X}]+\mathrm{C}[\mathrm{X}]^{2}+$ $\mathrm{D}[\mathrm{X}]^{3}$, Where A, B, C and D are constants and $\mathrm{I}_{\mathrm{m}}$ and Ic are the diffusion currents for metal and its complex respectively.

By knowing the values of $\mathrm{B}$ at two different concentration of $Y$, the values of $\beta_{11}$ and $\beta_{12}$ can be calculated.
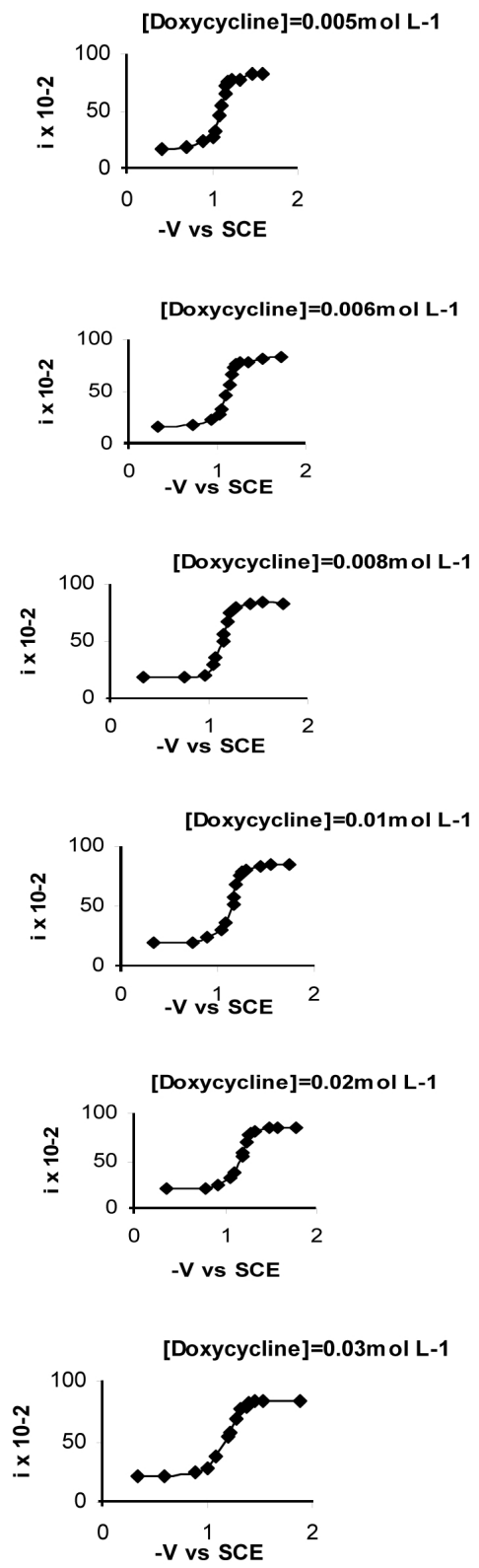

Figure 1. Polarograms of [Zn-doxycycline-cephaloglycin] system, [cephaloglycin] $=0.025 \mathrm{molL}^{-1}, \mathrm{X}$ axis $=(-$ V) volts, Yaxis = current (i) $\mu \mathrm{A}$. 

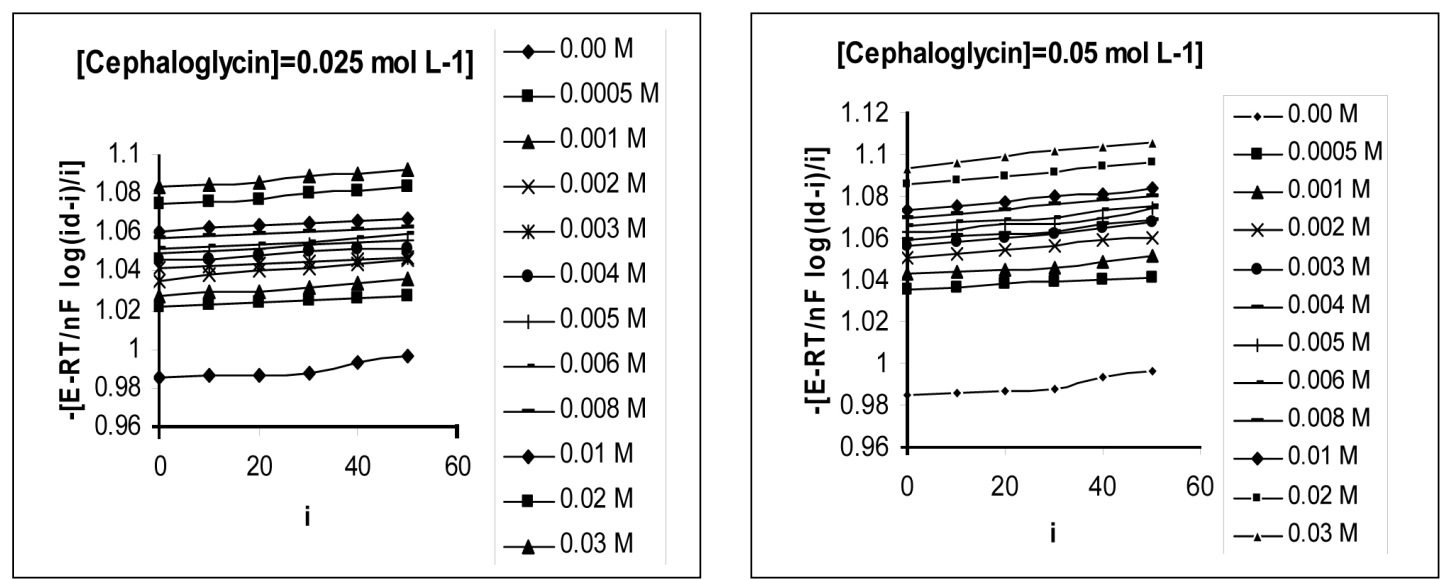

Figure 2. Plots between -[E-RT/nF $\left.\log \left(\mathrm{i}_{\mathrm{d}}-\mathrm{i}\right) / \mathrm{i}\right]$ vs i for $[\mathrm{Zn}$ - doxycycline - cephaloglycin] system.

Table 2. Stability constants values for $[\mathrm{Zn}-$ antibiotics - cephaloglycin] system. $\mathrm{pH}=7.30 \pm 0.01$, Supporting electrolyte $=1.0 \mathrm{~mol} \mathrm{~L}^{-1} \mathrm{NaClO}_{4}$, Triton $\mathrm{X}-100=0.001 \%, \mathrm{~T}=25.0^{\circ} \mathrm{C}$.

\begin{tabular}{lcccccccc}
\hline Ligands & $\log \beta_{01}$ & $\log \beta_{02}$ & $\log \beta_{10}$ & $\log \beta_{20}$ & $\log \beta_{30}$ & $\log \beta_{11}$ & $\log \beta_{12}$ & $\log \beta_{21}$ \\
\hline Doxycycline & - & - & 3.31 & 4.90 & 7.21 & 4.31 & 7.48 & 7.78 \\
Chlortetracycline & - & - & 4.40 & 7.61 & 9.50 & - & 7.81 & 9.68 \\
Oxytetracycline & - & - & 4.50 & 7.81 & 9.86 & 4.72 & 8.10 & 9.87 \\
Tetracycline & - & - & 4.80 & 8.01 & 9.91 & 5.10 & 8.31 & - \\
Minocycline & - & - & 4.85 & 8.13 & 9.98 & 5.24 & 8.43 & 10.00 \\
Amoxicillin & - & - & 4.88 & - & 10.01 & 5.48 & 8.49 & 10.13 \\
Chloramphenicol & - & - & 4.70 & 8.21 & 10.13 & - & 8.60 & 10.31 \\
Cephaloglycin & 2.14 & 3.22 & - & - & - & - & - & - \\
\hline
\end{tabular}
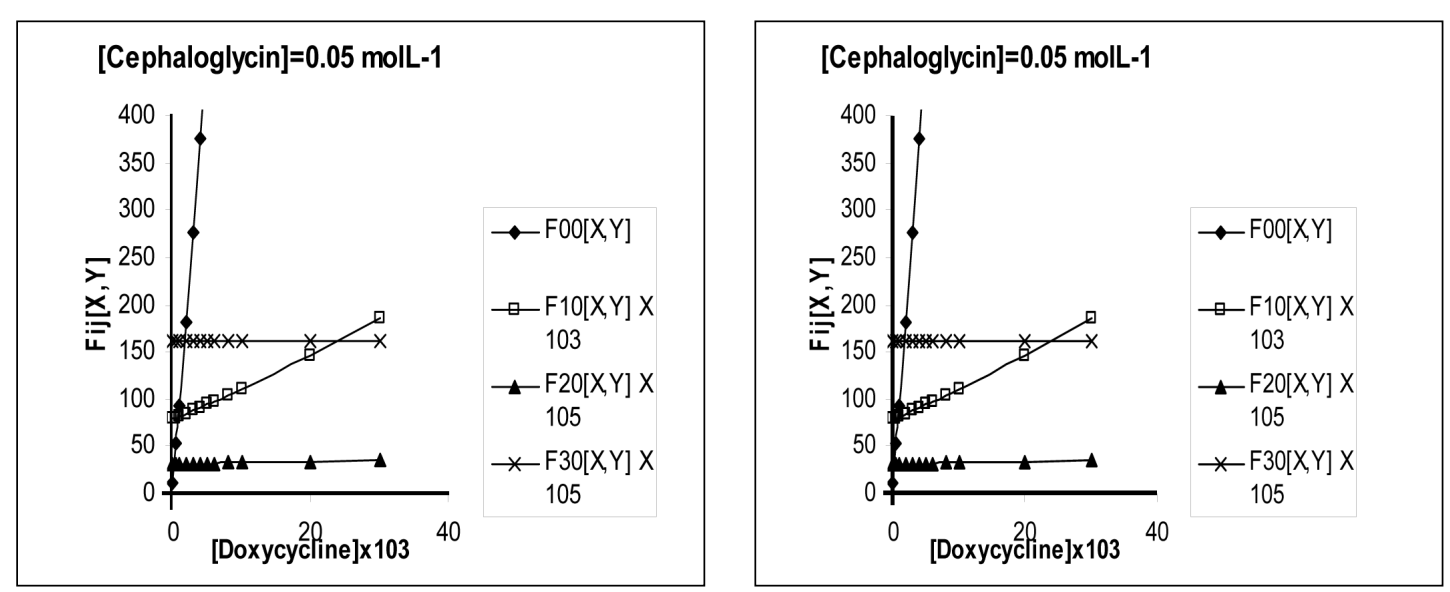

Figure 3. [Zn - doxycycline - cephaloglycin] system. 
Table 3. Kinetic parameters of [ $\mathrm{Zn}-$ doxycycline - cephaloglycin] system. Zn (II) $=0.5 \mathrm{~m} \mathrm{~mol} \mathrm{L-1}$ $\mathrm{pH}=7.30 \pm 0.01$, Supporting electrolyte $=1.0 \mathrm{~mol} \mathrm{~L}^{-1} \mathrm{NaClO}_{4}, \mathrm{~T}=25.0^{\circ} \mathrm{C}$. [cephaloglycin] $=0.025$ mol L-1; [cephaloglycin] $=0.05 \mathrm{~mol} \mathrm{~L}^{-1}$.

\begin{tabular}{|c|c|c|c|c|c|c|c|c|c|c|c|c|}
\hline $\begin{array}{c}\text { [Doxycy.] } \\
\text { x103 } \\
\mathrm{mol} \mathrm{L}^{-1}\end{array}$ & $\begin{array}{l}E_{1 / 2}{ }^{r} \\
-V \text { vs } \\
S C E\end{array}$ & $\begin{array}{c}\text { Slope } \\
\mathrm{mV}\end{array}$ & $\alpha$ & $\begin{array}{c}\lambda \\
\sec ^{-1 / 2}\end{array}$ & $\begin{array}{l}\text { Dx } 10^{3} \\
\mathrm{~cm}^{2} \mathrm{~s}^{-1}\end{array}$ & $\begin{array}{c}\mathrm{kx} \\
10^{3} \\
\mathrm{~cm} \mathrm{~s}^{-1}\end{array}$ & $\begin{array}{c}E_{1 / 2}^{r} \\
-V \text { vs } \\
\text { SCE }\end{array}$ & $\begin{array}{c}\text { Slope } \\
\mathrm{mV}\end{array}$ & $\alpha$ & $\begin{array}{c}\lambda \\
\sec ^{-1 / 2}\end{array}$ & $\begin{array}{l}\mathrm{D} \times 10^{3} \\
\mathrm{~cm}^{2} \mathrm{~s}^{-1}\end{array}$ & $\begin{array}{c}\mathrm{k} \times 10^{3} \\
\mathrm{~cm} \mathrm{~s}^{-1}\end{array}$ \\
\hline 0.00 & 1.0000 & 36 & 0.47 & 1.20 & 4.08 & 5.08 & 1.0000 & 36 & 0.47 & 1.20 & 4.08 & 5.08 \\
\hline 0.50 & 1.0350 & 38 & 0.45 & 1.35 & 4.01 & 5.43 & 1.0500 & 37 & 0.47 & 1.07 & 3.95 & 4.24 \\
\hline 1.00 & 1.0400 & 36 & 0.42 & 1.70 & 4.01 & 6.84 & 1.0600 & 38 & 0.53 & 1.35 & 3.88 & 5.25 \\
\hline 2.00 & 1.0550 & 37 & 0.51 & 1.51 & 3.95 & 5.25 & 1.0700 & 36 & 0.48 & 1.35 & 3.88 & 5.24 \\
\hline 3.00 & 1.0600 & 37 & 0.48 & 1.51 & 3.95 & 6.00 & 1.0750 & 36 & 0.51 & 1.51 & 3.75 & 5.70 \\
\hline 4.00 & 1.0650 & 37 & 0.50 & 1.35 & 3.88 & 5.25 & 1.0800 & 38 & 0.51 & 1.51 & 3.69 & 5.60 \\
\hline 5.00 & 1.0700 & 37 & 0.51 & 1.20 & 3.88 & 4.68 & 1.0850 & 38 & 0.57 & 1.07 & 3.69 & 3.96 \\
\hline 6.00 & 1.0750 & 37 & 0.59 & 1.20 & 3.82 & 4.60 & 1.0850 & 38 & 0.57 & 0.95 & 3.47 & 3.47 \\
\hline 8.00 & 1.0750 & 36 & 0.52 & 1.07 & 3.82 & 4.10 & 1.0850 & 38 & 0.42 & 1.70 & 3.62 & 6.17 \\
\hline 10.00 & 1.0800 & 37 & 0.57 & 1.35 & 3.75 & 5.08 & 1.0900 & 36 & 0.57 & 1.07 & 3.55 & 3.82 \\
\hline 20.00 & 1.0900 & 38 & 0.57 & 1.51 & 3.69 & 5.60 & 1.1000 & 36 & 0.55 & 0.95 & 3.55 & 3.40 \\
\hline 30.00 & 1.1000 & 36 & 0.42 & 1.35 & 3.62 & 8.52 & 1.1150 & 37 & 0.54 & 0.95 & 3.55 & 3.40 \\
\hline
\end{tabular}

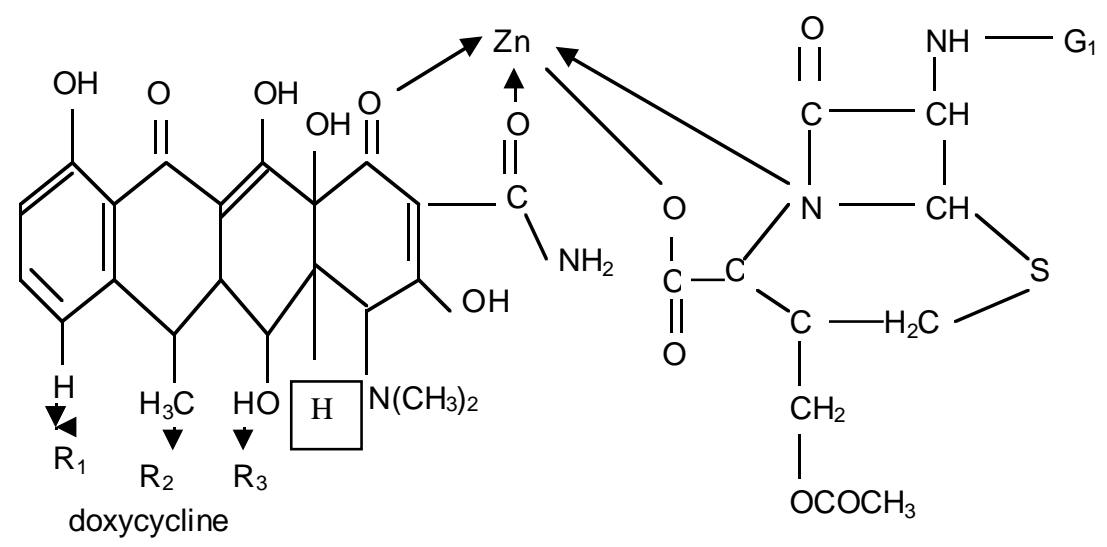<smiles>CC(=O)C(N)C1=CCC=CC1</smiles>

cephaloglycin

Figure 4. [Zn - doxycycline - cephaloglycin] system.

The values of stability constants $(\log \beta)$ varied from 2.14 to 10.31 which are reasonable [19] values; therefore, either cephaloglycin or [Zn - cephaloglycin] or [ $\mathrm{Zn}$ - antibiotics] or [ $\mathrm{Zn}$ - antibiotics - cephaloglycin] could be used against $\mathrm{Zn}$ toxicity.
For all complexes, Tamamushi and Tanaka methods [20-21] were used to determine the kinetic parameters. The plots between $\log (\mathrm{Z}$ $-1)$ vs. $\left(E_{1 / 2}\right.$ rev.- $\left.E\right)$ for $[\mathrm{Zn}$ - doxycycline cephaloglycin] were given in Fig. 5(a) and 5(b) respectively. The value of $Z$ was calculated by the 

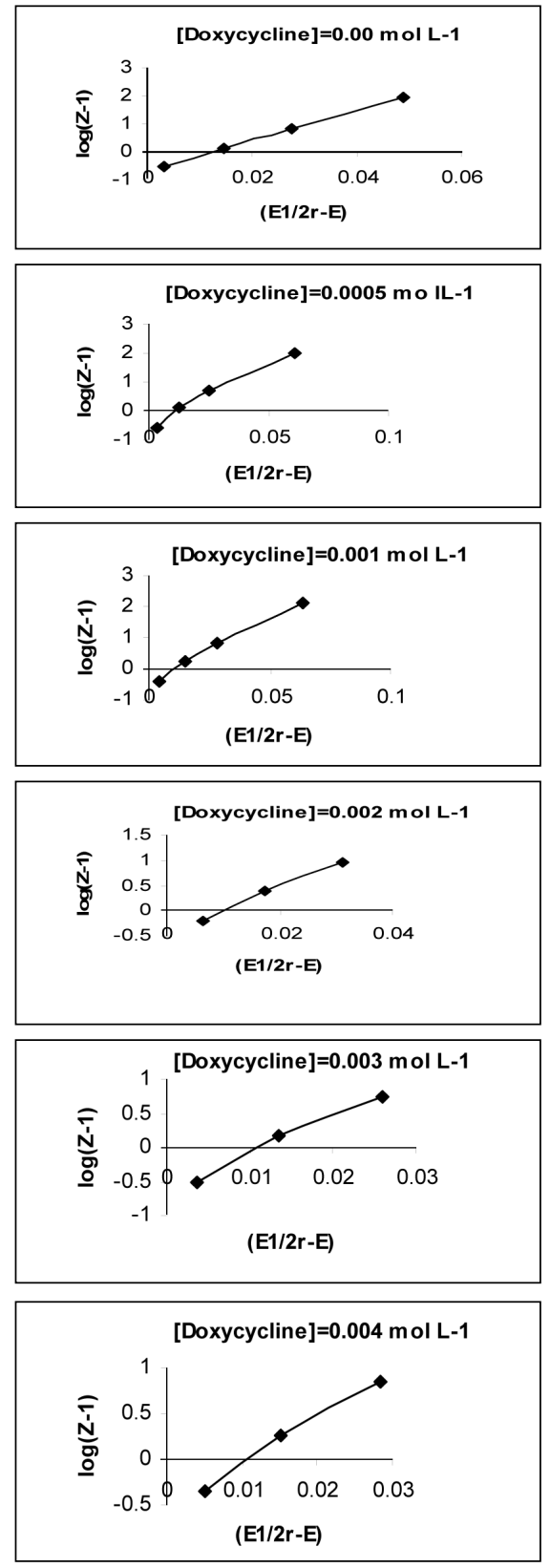
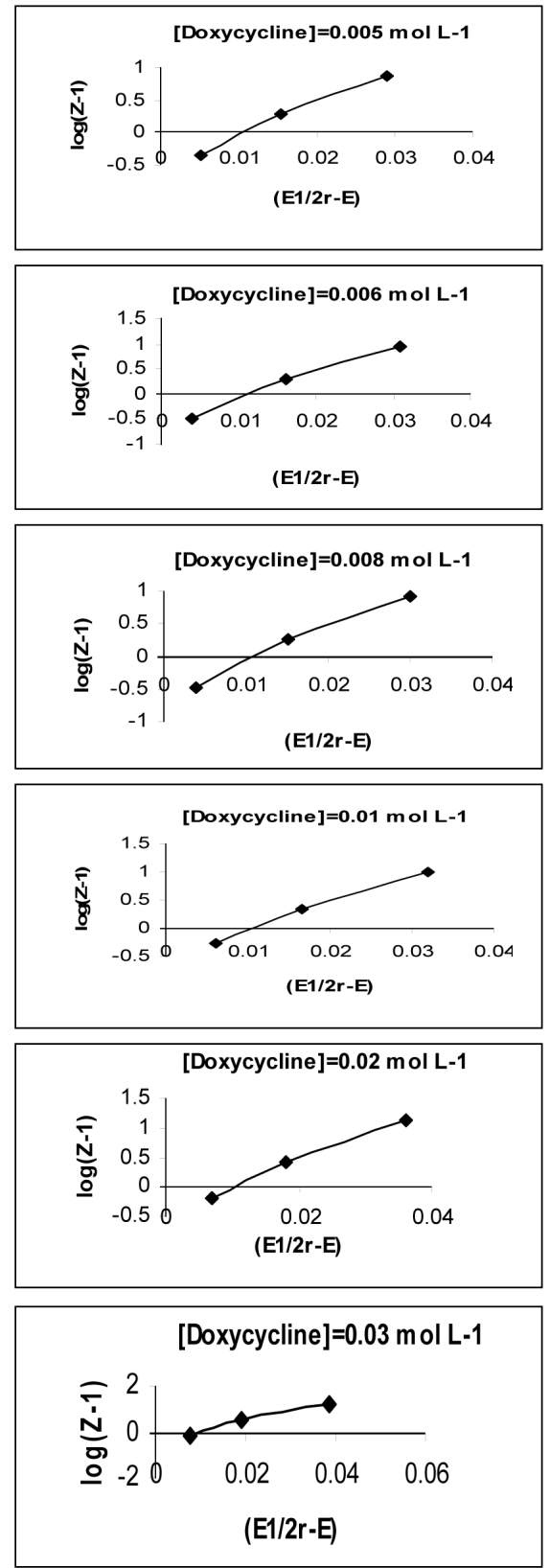

Figure 5(a). [Zn - doxycycline - cephaloglycin] system, [cephaloglycin] $=0.025 \mathrm{~mol} \mathrm{~L}^{-1}$.

following equation [20].

$\left.\mathrm{Z}=\operatorname{antilog}\left[\mathrm{nF} / 2.303 \mathrm{RT}\left(\mathrm{E}_{1 / 2}{ }^{\text {rev. }}-\mathrm{E}\right)\right)\right]+$ $\log \left(i_{d}-i\right) / i$, where $i_{d}$ is the diffusion current of the polarogram while $i$ is the current at $E$ of the same respectively.
The values of kinetic parameters were given in Table 3. In all the cases, the values of transfer coefficient $(\alpha)$ varied from 0.41 to 0.57 (0.50) confirmed that the 'Transition state' behaves between oxidant $(\mathrm{O})$ and reductant $(\mathrm{R})$ 

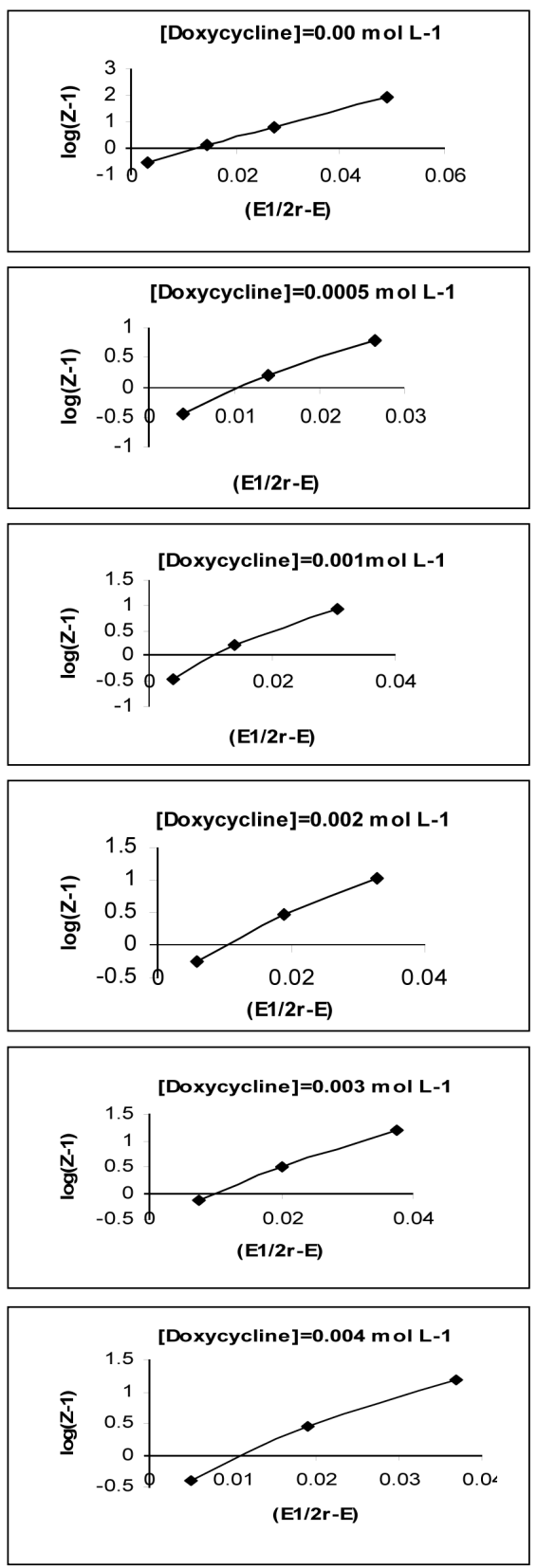
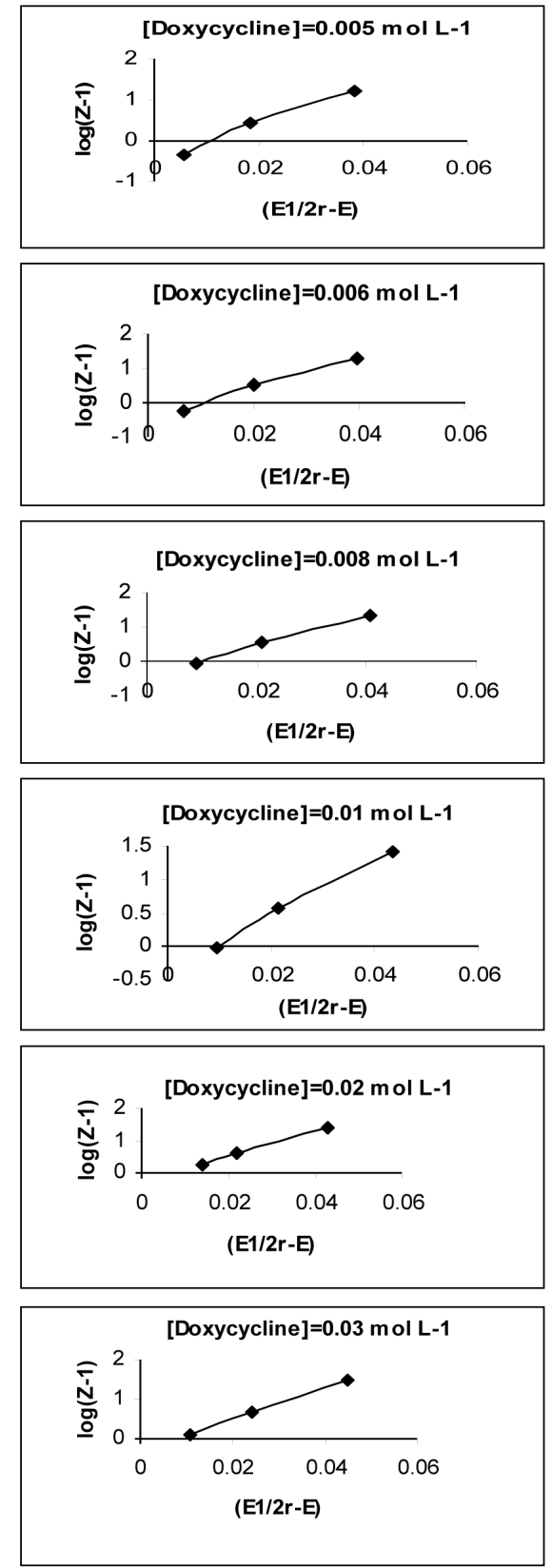

Figure 5(b). [Zn - doxycycline - cephaloglycin] system, [cephaloglycin $]=0.05 \mathrm{~mol} \mathrm{~L}$.

response to applied potential and it lies always between dropping mercury electrode and solution interface. A small variation in potential affects not only the rate but also the rate constant $(\mathrm{k})$ of the electrochemical reaction greatly. The values of $\mathrm{k}$ varied from $(2.21-8.52) \times 10^{-3} \mathrm{~cm} / \mathrm{sec}$. confirmed the quasireversible nature of the electrode processes. 
The oxidant $\mathrm{Zn}$ (II) or complex species) reduces at d.m.e. can be given by the following equation:

$\mathrm{O}+\mathrm{ne} \stackrel{\mathrm{R}}{\mathrm{R}}$

The rate constant of the above reaction can be given by the following equation [20].

$\mathrm{k}_{\text {red. }}=\mathrm{k}^{0} \mathrm{e}^{-\alpha \mathrm{nF} / \mathrm{RT}}(\mathrm{E}-\mathrm{E} 0)$

Where, $\mathrm{k}^{0}$ is the specific heterogeneous rate constant and $\mathrm{E}^{0}$ being the standard redox potential of the system. In the present case, the concentration of depolarizer is $0.5 \mathrm{mmol} \mathrm{L}^{-1}$ therefore; no specific adsorption of ions is at d.m.e [2]. The values of rate constant $\mathrm{k}$ are also of the order of $10^{-3} \mathrm{~cm} / \mathrm{sec}$. therefore, the electrode processes were quasireversible [20]. When the concentration of electro active species is high (1.0 mmolL-1 or more)[2], adsorption of ions becomes appreciable and the Helmholtz plane is now called the inner Helmholtz plane remains at the locus of adsorbed ions and the outer Helmholtz plane corresponds to the closest approach to the electrode outside the range of adsorption forces. Thereafter, Gouy Chapman diffuse double layer is present. In the present case, no adsorption of ions is there at d.m.e. because the concentration of $\mathrm{Zn}$ (II) is $0.5 \mathrm{mmol} \mathrm{L}^{-1}$ [1-2]. When some potential is applied between d.m.e. and solution interface, the residual current is observed as a result of continual charging of mercury drops and also the electrical double layer is formed in the vicinity of d.m.e. This current is a sum of Faraday current observed due to the reduction of impurities (if present) and non Faraday current as a result of the formation of electrical double layer in the vicinity of dropping mercury electrode. At d.m.e., Helmholtz layer is formed due to the presence of cations such as $\mathrm{Na}^{+}$and $\mathrm{Zn}^{2+}$ and complex species. After the Helmholtz layer, there is a diffuse double layer of Gouy Chapman. When the applied potential became equal to the deposition potential of the electro active species (here complex species), the electroactive species started to reduce at d.m.e. in a quantum mechanical tunneling zone which is about $2 \mathrm{~nm}$ from d.m.e. The depletion of the concentration of electro active species is compensated by the complex species moving from bulk of the solution to d.m.e. by diffusion. But diffusion is a slow process - therefore, a concentration gradient is established at d.m.e. (Helmholtz layer is now diffusion layer). When all the oxidant reaching the d.m.e. gets reduced, the current observed is the limiting current.

\section{Conclusion}

In this study, kinetic parameters viz. $\alpha, \lambda$ and $\mathrm{k}$ have been determined. The values of transfer coefficient varied from 0.41 to $0.55(0.50)$ confirmed that the 'transition state' behaves between reactant and product response to applied potential and it adjusts itself in such a way that it always located in the mid of dropping mercury electrode and solution interface. The exact nature of electrode processes was quasireversible which was confirmed by the values of rate constant $(\mathrm{k})$. The values of $\mathrm{D}$ and $\lambda$ were also as expected [21$22]$. The values of stability constant $(\log \beta)$ confirmed that these drugs or their metal complexes could be used against $\mathrm{Zn}$ toxicity [19].

\section{Acknowledgement}

The author thanks the Head, Department of Chemistry, Dr. H. S. Gour University, Sagar, M. P., India for providing the laboratory facilities and MAPCOST, Bhopal and DST, New Delhi for financial support.

Received July 212008

Accepted August 292008

\section{References}

[1] M. Breiter, M, Kleinerman, P. Delahay, J. Am. Chem. Soc. 80(1996) 5111.

[2] L. Meites, Polarographic Technique, Interscience Pub., New York, 1965

[3] F. Khan, Oxid. Commun. 28 (2007) 937.

[4] P. W. Atkins, Physical Chemistry, Oxford Univ. Press, Oxford, 1986.

[5] F. Khan, J. Chin. Chem. Soc. 54 (2007) 673

[6] H. A. Latinen, E. I. Onstott., J. Am. Chem. Soc. 72 (1950) 4565.

[7] L. S. Goodman, A.Gilman, The Pharmacological Basis of Therapeutics, London, MacMillan, 1975. 
[8] C. R. Dawson, H. B. Ostler, L. Hanna, I. Hoshiwara, E. J. Jawetz, Infect. Dis. 124 (1971) 255.

[9] F. Khan, F. Khan, J. Chin. Chem. Soc. 52 (2005) 569.

[10] A. Kesharwani, F. Khan, Bull. Electrochem. 18 (2002) 413

[11] T. Devries, J. L. Kroon, J. Am. Chem. Soc. 75 (1953) 2484.

[12] P. J. Gellings, Electrochem. Ber. Bunsenges Phys. Chem. 66 (1962) 477.

[13] J. J. Lingane, Chem. Rev. 29 (1941) 32

[14] W. B. Schaap, D. L. McMaster, J. Am. Chem. Soc. 82 (1961) 4699.

[15] F. Khan, L. Tantuvay, J. Pharm. Biomed. Anal. 27 (2002) 933.

[16] F. Khan,. L. Tantuvay, Trans. SAEST. 35 (2000) 79.
[17] C. R. Stephens, L. H. Conover, R. Pasternack, F. A. Hochstein, W. T. Moreland, P. P. Regna, F. J. Pilgrim, K. J. Brunnings, R. B. Woodward, J. Am. Chem. Soc. 76 (1954) 3568.

[18] A. E. Martell, M. Calvin, Chemistry of Metal Chelate Compounds, London: Prentice Hall, 1953

[19] M. D. Walker, D. R. Williams, J. Chem. Soc. (Dalton) 19741186.

[20] R. Tamamushi, N. Tanaka, Z. Phys. Chem. Neue Folge. 39 (1963). 117.

[21] R. Tamamushi, K. Ishibashi, N. Tanaka, Z. Phys. Chem. Neue Folge 35 (1962) 209.

[22] P. Delahay, Double Layer and Electrode Kinetics, Interscience Pub., New York, 1965. 